\title{
The Role of Nonmedical Therapeutic Approaches in the Rehabilitation of Complex Regional Pain Syndrome
}

\author{
Charlotte Boichat ${ }^{1,2,3}$ \\ Alison Llewellyn ${ }^{1,2,3, *}$ \\ Sharon Grieve ${ }^{1,2,3}$

\section{Candida McCabe $e^{1,3,4}$}

\author{
Address \\ *,1Royal United Hospitals Bath NHS Foundation Trust, Combe Park, Bath, BA1 3NG, \\ UK \\ Email: Alison.Llewellyn@uwe.ac.uk \\ ${ }^{2}$ Department of Nursing and Midwifery, University of the West of England, Glen- \\ side Campus, Blackberry Hill, Bristol, BS16 1DD, UK \\ ${ }^{3}$ Dorothy House Hospice Care, Winsley, Bradford on Avon, BA15 2LE, UK \\ ${ }^{4}$ Florence Nightingale Foundation, 11-13 Cavendish Square, London, UK
}

Published online: 29 July 2020

(C) The Author(s) 2020

This article is part of the Topical Collection on Pain in Rheumatology

Keywords Complex Regional Pain Syndrome · Therapy · Therapeutic · Rehabilitation · Patient education

\section{Abstract}

Purpose of the Review Nonmedical therapeutic approaches are fundamental to the management of of Complex Regional Pain Syndrome (CRPS) in order to promote the best outcome for patients. This review focuses on three key approaches underpinning CRPS rehabilitation, namely, physiotherapy and occupational therapy, psychological approaches and education and self-management.

Recent Findings Recently published European standards outline the quality of therapeutic care that people with CRPS must receive. Early initiated therapy is essential to optimise outcomes, underpinned by patient education. Therapists should promote early movement of the affected limb and encourage re-engagement with usual activities as immobilisation is known to have negative outcomes. There is evidence to support the possible long-term benefit of graded motor imagery and mirror therapy. Psychological assessment should include identification of depression and post-traumatic stress disorder, as treatment of 
these conditions may improve the trajectory of CRPS. Novel therapies include neurocognitive approaches and those addressing spatial bias, both of which should provide a focus for future research.

Summary There exists a broad range of nonmedical therapeutic approaches to rehabilitation for CPRS that are thought to be important. However, the evidence for their efficacy is limited. Further research using standardised outcomes would be helpful in developing targeted therapies for the future.

\section{Introduction}

Complex regional pain syndrome (CRPS) is a persistent condition, of which the principal symptom is intense pain, commonly in a distal limb [1]. Other features include changes to limb temperature, colour, nail and hair growth and impaired limb function (see Table 1) [2•]. CRPS exhibits similar clinical manifestations as other rheumatology conditions, pain, fatigue and/or muscle weakness [3, 4]; however, for CRPS, the pain cannot be explained by the pathology. It has two subtypes according to the absence (CRPS 1) or presence (CRPS 2) of an associated nerve lesion [1]. The aetiology of CRPS is unknown, although it is likely due to many components including inflammation, dysfunction within the nervous system and changes within the cortex of the brain $[5 \bullet \bullet]$. Precipitating factors can include trauma and surgery $[1,2 \bullet, 6]$; however, CRPS can also occur spontaneously with no identifiable inciting event [7]. It is also important to recognise that psychological factors in themselves do not cause CRPS $[8,9]$.

There is no definitive test for CRPS and so diagnosis is based on fulfilment of the Budapest criteria [2•]. Although there is no cure, early intervention should significantly improve outcomes $[10,11]$ and we know that, for patients, amongst the most valued outcomes include functional improvement, as well as relief of pain [12].

Recent literature has challenged the legitimacy of CRPS as a condition, for reasons including overdiagnosis, due to the lack of specificity of the diagnostic criteria and the absence of an objective test for CRPS [13-15]. The recently published European Standards for CRPS may address these challenges as it is now stated the Budapest diagnostic criteria must be used $[2 \bullet, 16 \bullet \bullet$. In addition, recommendations for the first standardised core outcome measurement set for CRPS clinical studies

\section{Table 1. Budapest diagnostic criteria [2•]}

All of the following must apply:

- The patient has continuing pain which is disproportionate to any inciting event.

- The patient has at least one sign in two or more of the categories.

- The patient reports at least one symptom in three or more of the categories.

- No other diagnosis can better explain the signs and symptoms.

Categories

Sensory

Sudomotor/oedema

Allodynia (to light touch and/or temperature sensation and/or deep somatic pressure and/or hyperalgesia (to pin prick)

Vasomotor

Temperature asymmetry and/or skin colour changes and/or skin colour asymmetry

0edema and/or sweating changes and/or sweating asymmetry

Motor/trophic

Decreased range of motion and/or motor dysfunction (weakness, tremor, dystonia) and/or trophic changes (hair/skin/nails) 
will facilitate multi-centre collaborative research to attain sufficient sample sizes for meaningful studies [17]. It is anticipated that a future, large, consistent data set could be used to gain a better understanding of the mechanisms driving CRPS and inform targeted treatment approaches.

The European incidence of CRPS is $20-26 / 100,000$ person years [18]; however, these data are over 10 years old and require updating. More recent data, from a USA national inpatient database, found CRPS disproportionately affects more women than men, and that it peaks in prevalence in middle age [19]. Although many cases will resolve within 6 to 13 months, a recent systematic review found that between 22 and $64 \%$ of patients experience persistent symptoms $\geq 3$ years after diagnosis [20] and, as a consequence, CRPS has a significant impact on the health economy and health-related quality of life [21]. A recent retrospective analysis of the Swiss National Accident Insurance database reported high economic costs associated with CRPS [22]. Average treatment costs were found to be 13 times greater, and the number of working days lost was 20 times higher, in patients with CRPS after an accident, compared with those without CRPS [22].

Current interdisciplinary treatment approaches include those which address the pathophysiology of CRPS with the aim to reduce pain, optimise limb function and promote self-management. Published country-specific guidelines and European Standards promote best practice in CRPS diagnosis, treatment and management $[5 \bullet \bullet, 16 \bullet \bullet, 23 \bullet, 24 \bullet]$. In the United Kingdom (UK), professional guidelines recommend four key treatment approaches $[5 \bullet \bullet]$. Three of these approaches will inform this article namely, physical and vocational rehabilitation, psychological interventions and patient information and education to support self-management. The fourth approach: pain relief, comprising medications and procedures, will not be addressed in this article. Moreover, beyond some pharmacological approaches to pain reduction, there is scant evidence for the efficacy of medical-surgical procedures. For example, surgical sympathectomy and sympathetic blockade are considered ineffective in reducing pain in CRPS, and there is little evidence that spinal cord stimulation has greater effect in the longer term than physical therapy alone $[25 \bullet]$.

The authors are affiliated with a national, specialist rehabilitation service for CRPS and therefore, this article will utilise this expertise and present an overview of the current, interdisciplinary nonmedical treatment approaches. It is acknowledged however, there is a need for further evidence to evaluate the effectiveness of interdisciplinary approaches [25•]. The quality of the literature presented will not be independently assessed.

\section{Therapeutic approaches}

\section{Physiotherapy and occupational therapy}

Guidelines for the treatment of CRPS recommend interdisciplinary approaches which include physiotherapy and occupational therapy practice $[5 \bullet \bullet, 16 \bullet \bullet, 23 \bullet, 24 \bullet]$. Indeed, to shorten the disease course and optimise outcomes, early referral to physiotherapy and occupational therapy is considered imperative $[5 \bullet \bullet, 16 \bullet \bullet, 26]$. Therapists in the community will frequently be those healthcare professionals who see people with CRPS early in their treatment pathways and these therapists commonly make the initial diagnosis of CRPS or refer patients for diagnosis by specialist services. Once CRPS has been identified, the therapist's role is to encourage early movement of the affected limb, provide education on CRPS, promote patient self-management and facilitate behaviour change in order to encourage patient-initiated activities $[5 \bullet \bullet, 27]$.

Guidelines recommend that therapists should encourage people with suspected or confirmed CRPS to exercise the limb or to engage in gentle functional activity as soon as possible, as it is recognised that immobilisation has deleterious consequences for successful resolution $[5 \bullet \bullet, 26]$. Similarly, it is 
recommended that activity participation is both assessed early and repeatedly $[16 \bullet \bullet]$. Other physical and occupational therapy approaches are numerous and include graded exposure, manual therapy, electrotherapy (e.g. transcutaneous electrical nerve stimulation (TENS), desensitisation activities, mirror visual feedback, massage, relaxation, sleep hygiene, coping skills, hydrotherapy and vocational support $[5 \bullet \bullet, 28]$.

Novel physical therapies are considered helpful to patients with CRPS in focussing on normalising the sensory-motor feedback loop [26]. CRPS-specific rehabilitation techniques include tactile discrimination, graded motor imagery (GMI), conflict-allodynia re-education and strategies to address body perception disturbance [ $5 \bullet \bullet$. A list of therapeutic approaches, as included in the 2018 UK Royal College of Physicians guidance is given in Table 2.

Provided in combination with medical management, physiotherapy treatments have been reported to have a positive effect on reducing pain and other CRPS symptoms $[29,30]$. Both physiotherapy and occupation therapies have been found to lead to reduced physical impairment [31] and to have particular benefit in supporting the restoration of activities of daily living when provided in combination [32]. The somatosensory rehabilitation method (consisting of distant vibrotactile counter stimulation, application of therapeutic vibration and avoidance of touch stimuli that evoke pain) may be effective for addressing CRPS-related allodynia [33], and preliminary findings from a small retrospective study reported that body perception disturbance was found to reduce immediately following interdisciplinary clinical rehabilitation for CRPS [34]. Whilst it must be acknowledged that the evidence of therapy approaches

Table 2. Therapeutic approaches to the treatment of CRPS [5••]

Therapeutic approaches

- Patient education and support

- Self-administered tactile and thermal desensitisation with the aim of normalising touch perception

- General exercises and strengthening

- Functional activities

- Mirror visual feedback

- Gait re-education

- Transcutaneous electrical nerve stimulation (TENS)

- Postural control

- Pacing, prioritising and planning activities

- Goal setting

- Relaxation techniques

- Coping skills

- Hydrotherapy

- Sleep hygiene

- Oedema control strategies

- Vocational support

- Facilitating self-management of condition

- Splinting (generally short term, in acute CRPS)
CRPS-specific rehabilitation techniques

- Graded motor imagery

- Tactile discrimination

- Strategies to correct body perception disturbance, involving looking, touching and thinking about the affected body part

- Mental visualisation to normalise altered size and form perception of affected body part

- Functional movement techniques to improve motor control and awareness of affected limb position

- Principles of stress loading

- Conflict allodynia re-education to reduce fear of physical contact with others in community settings

- Management of CRPS-related dystonia 
is limited in terms of sustained clinically important differences at fourand six-month follow-up [25•], a Cochrane systematic review by Smart et al. [35] concluded that there may be possible long-term benefit from GMI and mirror therapy, albeit accepting that the quality of supporting evidence for this supposition was very low.

There is extensive research showing that psychological factors have an influence on outcomes in a range of chronic pain conditions [36-39]. Having CRPS may affect a patient's ability to work, participate in social activities and it frequently decreases a person's quality of life [40].

There are relatively few studies examining psychological factors in patients with CRPS. There is no evidence that CRPS has a psychological origin or that anxiety and depression are predictors of the condition [8, 41]. However, psychological symptoms, such as anxiety and depression, frequently develop if the condition persists and tailored interventions to address these symptoms should be part of the integrated treatment approach $[5 \bullet \bullet, 42]$. In a review, Lohnberg and Altmaier [9] concluded that CRPS results in depression, anxiety and reduced quality of life for some individuals. However, CRPS patients have been found to have higher levels of depression than other pain patients [43], and to have impaired emotional empathetic abilities compared with healthy controls [44]. Other studies have shown no difference between CRPS and low back pain patients in terms of level of distress [45].

A number of studies have shown associations between psychological factors in those with CRPS and outcomes such as disability. In a cross-sectional study, higher levels of depression were associated with greater disability [42], and in comparison with patients with low back pain, depression in those with CRPS had a stronger association with disability [45]. Prospective studies have revealed that anxiety is related to CRPS outcomes; a high level of anxiety was associated with a higher risk of developing CRPS after a fracture [46], high anxiety after surgery predicted worse CRPS symptoms at 6 months [47] and lower anxiety at baseline was related to lower pain intensity over the following 12 months [48].

Additionally, in people with CRPS, those with higher pain-related fear have been found to be more disabled than those who were less fearful [49]. Similarly, a study by Bean et al. [48] found those people with lower pain-related fear were less disabled over a 12-month follow-up period than those who were more fearful. These findings are consistent with the Fear Avoidance Model [50] which suggests that psychological factors including pain-related fear can lead to an avoidance of movement.

Depression, anxiety and current stress have also been found to be associated with body perception disturbance [51]. Subsequent disengagement and disuse of the affected limb, commonly seen in CRPS [48, 52], are thought to be contributing and maintaining factors to the condition and which may lead to cortical changes [53]. In patients with CRPS, psychological factors such as depression, anxiety and pain-related fear, could therefore operate through both biological (e.g. neuroendocrine and immunological processes) $[9,23 \bullet]$ and behavioural processes such as avoidance and disuse [48, 52]. Treatment for body perception disturbance therefore often focuses on encouraging attention to, and reengagement with, the affected limb. 
Since CRPS patients may have higher levels of affective distress, and research shows an association between psychological factors and outcomes, it is important to consider psychological therapy in the treatment of CRPS. Indeed, psychological therapy is one of the four pillars of treatment in the UK Royal College

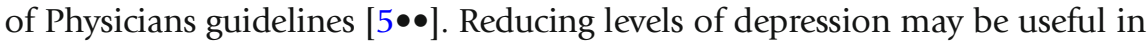
the prevention of poor long-term outcomes [42] and chronic pain more generally [37]. A recent cross-sectional study demonstrated a high prevalence of posttraumatic stress disorder (PTSD) in those with CRPS, compared with those without the condition [54]. Speck et al. [54] identified PTSD as a risk factor for CRPS but the reason for this is, as yet, unknown and requires further investigation. It is possible PTSD initiates a fear of moving the limb which has a negative impact on outcome [54].

Cognitive and behavioural therapies can be utilised to improve outcomes for patients [55]. Psychological treatments can include acceptance and commitment therapy, relaxation techniques, biofeedback, the management of stressors and exposure therapy $[56,57]$. An interdisciplinary approach including psychosocial factors is regarded by some as essential [9] with psychological treatments in the early stages of CRPS recommended [43, 48]. Currently, psychological therapy is included in many interdisciplinary pain management programs. A biopsychosocial model is deemed appropriate for understanding and treating CRPS [58]. However, more CRPS-specific research in this area is necessary especially high-quality randomized controlled trials on current treatment approaches [52, 59].

\section{Education and self-management}

Underlying therapy practice is the need for appropriate education to support patients in the self-management of their condition [40]. A core component of the UK guidelines for the treatment of CRPS is the provision of

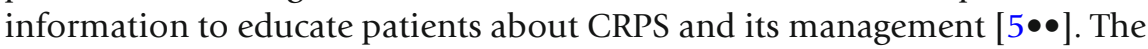
recently published 'European Standards for the Diagnosis and Management of CRPS' state all patients must receive adequate information on 'i) CRPS, ii) its causation (including the limits of current scientific knowledge), iii) its natural course, iv) signs and symptoms including body perception abnormalities, v) typical outcomes, and vi) treatment options' [(16••], p646). Provision of information should be soon after diagnosis and repeated as necessary, if the condition progresses [16••]. The Standards emphasise how evidence-based information is crucial to enable an individual to adopt selfmanagement strategies that will give them the best chance of rehabilitation

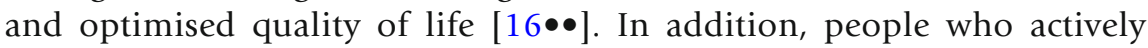
manage their own healthcare have been shown to have more positive outcomes than those who are disengaged [60].

Prior to the publication of the European Standards [16••] there was a dearth of guidance about best practice. To date, a lack of understanding of CRPS, its management and potential outcomes has been reported by those with the condition [61-63]. This may lead to poor engagement with rehabilitation and self-management strategies.

It is the responsibility of all health disciplines caring for people with

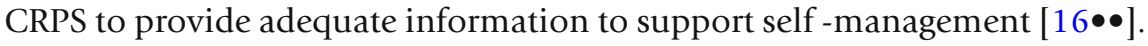


However, there is evidence of conflicting and outdated information provided by some health professionals [62-65]. The challenge is to provide health professionals, who are the first point of contact for those presenting with CRPS, with easy access to high quality, recommended resources which can be shared with the patient. The quality of information sources used by patients has been shown to influence the quality of their treatment decision-making [66-68]. Raising awareness of the Standards and Guidelines for CRPS will help practitioners to be signposted to further resources,

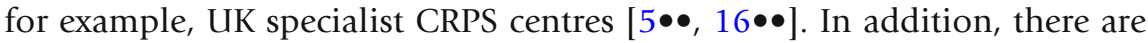
an increasing number of resources available for patients and health professionals, many of which have been co-designed to include information considered important to the person with CRPS. The CRPS International Research Consortium (https://www.crpsconsortium.org/) and the International Association for the Study of Pain CRPS Special Interest Group (https://www.iasp-pain.org/Membership/SIGDetail.aspx? ItemNumber= 753) offer health professionals the opportunity to connect and collaborate, with a focus on new developments in the field.

Encouragingly, a recent international survey of current practice in CRPS rehabilitation reported that education, along with physical exercise, was the most frequently used rehabilitation approach however no detail was provided as to what the education comprised [40]. In addition, the European Pain Federation CRPS task force is currently undertaking a Delphi survey of healthcare professionals and patients, to explore the education needs of people with CRPS and to identify recommended resources (unpublished). Once published, this will be a useful article to signpost patients and health professionals to current resources; however, future work will be needed to maintain its contemporaneous nature.

\section{Other and emerging therapies}

The complex and recalcitrant nature of CRPS means novel treatments continue to emerge. For example, the potential benefits of massage therapy integrated with clinical hypnosis have been recently reported [69]. Research has also begun to explore neurophysiological approaches. Evidence from a number of studies suggests a structural reorganisation of the brain is associated with chronic pain [70, 71]. Such reorganisation has been recognised in CRPS and its association with pain experience is supported by studies of how CRPS patients represent and attend to their affected limb $[72,73]$ and of the consequent impacts of visual neglect and emotional changes about the painful limb on motor and autonomic function [7476]. Prism Adaptation originated as a behavioural intervention, developed to moderate attention deficits in post-stroke hemispatial neglect. However, its potential role in addressing spatial biases in CRPS has more recently become a topic of investigation and has led to studies of its efficacy as a treatment approach [77-80]. Whilst these have demonstrated positive effects, they have been limited by small sample sizes and design restrictions [81]. It is therefore hoped that further research will improve our understanding of the known neurophysiological changes that occur in CRPS and of the potential of Prism Adaptation as a novel method of pain relief and symptom improvement. 
A similar line of current enquiry in CRPS is the application of therapeutic exercises based on the neurocognitive rehabilitation theory proposed by neurologist Carlo Perfetti [82]. Previously used to restore functionality after stroke, this theory hypothesises that enabling patients to learn new patterns of interaction with their surroundings, through perceptive and proprioceptive attention, supports sensory-motor recovery via the activation of cognitive processes. It has been found to be effective in upper-extremity rehabilitation post-stroke $[83,84]$ and has also been reported to be effective in orthopaedic rehabilitation [85, 86] and Parkinson's disease [87]. More recent clinical evidence from a UK specialist CRPS rehabilitation programme has demonstrated improved sensory perception, reduction in pain and improved function following the application of the neurocognitive approach. This may therefore be a fruitful avenue for future CRPS treatment studies.

Another novel proposition in the treatment of CRPS is the role of visual illusions in pain reduction. It is postulated that targeting central processing through visual illusions can rectify the maladaptive sense of dis-ownership of a painful limb that can occur for some who have the condition. Pain reduction has been found to occur when the perceived size of an affected limb is visually altered [88] and changing the visual appearance of an affected limb according to patients' descriptions of how they would like the limb to appear has also demonstrated improvements to perceived limb ownership [89]. The use of mediated virtual reality with patients with recalcitrant CRPS is promising, with a recent study finding therapeutic effect from a single exposure to a digitally manipulated image of the affected limb, both in terms of pain and body perception disturbance [90]. Use of the rubber hand illusion [91] has progressed our understanding of body dis-ownership in CRPS [92] and has similarly been proposed as a potential means of working toward the toleration of touch on a CRPS-affected limb [71].

Building on studies in the phantom limb pain population [93], sensory retraining using repeated, manual application of different textiles or stimuli to the 'affected', and 'unaffected' limb has been shown to reduce pain in people with CRPS [53, 94] More recently, Schmid et al. [95] demonstrated how people with CRPS reported a reduction in pain following a 2-week training programme using braille-like haptic tasks. Importantly, pain reduction correlated with an increased duration of training [95]. Recent advances have developed a prototype electrical Sensory Training System for home use, which can improve two-point discrimination [96]. Current research is investigating the optimum dose for pain reduction using this system (unpublished).

\section{Conclusion}

There exists a broad range of therapeutic approaches to rehabilitation for CPRS that are thought to be important. However, the evidence for their efficacy is limited. Further research using standardised outcomes would be helpful in developing targeted therapies for the future. 


\section{Compliance With Ethical Standards}

\section{Conflict of Interest}

SG is a National Institute for Health Research (NIHR) Senior Nurse and Midwife Research Leader. The views expressed in this article are those of the author(s) and not necessarily those of the NIHR, or the Department of Health and Social Care.

\section{Human and Animal Rights}

All reported studies/experiments with human or animal subjects performed by the authors have been previously published and complied with all applicable ethical standards (including the Helsinki declaration and its amendments, institutional/national research committee standards and international/national/institutional guidelines).

Open Access This article is licensed under a Creative Commons Attribution 4.0 International License, which permits use, sharing, adaptation, distribution and reproduction in any medium or format, as long as you give appropriate credit to the original author(s) and the source, provide a link to the Creative Commons licence, and indicate if changes were made. The images or other third party material in this article are included in the article's Creative Commons licence, unless indicated otherwise in a credit line to the material. If material is not included in the article's Creative Commons licence and your intended use is not permitted by statutory regulation or exceeds the permitted use, you will need to obtain permission directly from the copyright holder. To view a copy of this licence, visit http://creativecommons.org/licenses/by/4.0/.

\section{References and Recommended Reading}

Papers of particular interest, published recently, have been highlighted as:

- Of importance

- Of major importance

1. Birklein F, Dimova V. Complex regional pain syndrome-up-to-date. Pain Reports [internet]. 2017;2(6). Available from: https://www.ncbi.nlm.nih.gov/pmc/ articles/PMC5741324/

2.• Harden RN, Bruehl S, Perez RSGM, Birklein F, Marinus J, Maihofner C, et al. Validation of proposed diagnostic criteria (the "budapest Criteria") for complex regional pain syndrome. Pain. 2010;150(2):268-7.

European standards for the diagnosis and management of CRPS advocate the use of these criteria.

3. Bucourt E, Martaillé V, Goupille P, Joncker-Vannier I, Huttenberger B, Réveillère $\mathrm{C}$, et al. A comparative study of fibromyalgia, rheumatoid arthritis, spondyloarthritis, and Sjögren's syndrome; impact of the disease on quality of life, psychological adjustment, and use of coping strategies. Pain Med. 2019.

4. Yamada T, Steinz MM, Kenne E, Lanner JT. Muscle weakness in rheumatoid arthritis: the role of $\mathrm{Ca} 2+$ and free radical signaling. EBioMedicine. 2017;23:12-9.

5.• Goebel A, Barker C, Turner-Stokes L. Complex regional pain syndrome in adults. 2nd ed. London: Royal College of Physicians; 2018.
These UK recommendations describe best practice using an integrated, interdisciplinary, treatment approach for the diagnosis, referral and management of CRPS.

6. Nicholas M, Vlaeyen JWS, Rief W, Barke A, Aziz Q, Benoliel R, et al. The IASP classification of chronic pain for ICD-11: chronic primary pain. Pain. 2019;160(1):28-37.

7. de Rooij AM, Perez RSGM, Huygen FJ, van Eijs F, van Kleef M, Bauer MCR, et al. Spontaneous onset of complex regional pain syndrome. Eur J Pain. 2010;14(5):510-3.

8. Beerthuizen A, van't Spijker A, Huygen FJPM, Klein J, de Wit $\mathrm{R}$. Is there an association between psychological factors and the complex regional pain syndrome type 1 (CRPS1) in adults? A systematic review. Pain. 2009; 145(1-2):52-9.

9. Lohnberg JA, Altmaier EM. A review of psychosocial factors in complex regional pain syndrome. J Clin Psychol Med Settings. 2013;20(2):247-54.

10. Gillespie S, Cowell F, Cheung G, Brown D. Can we reduce the incidence of complex regional pain syndrome type I in distal radius fractures? The Liverpool experience. Hand Ther. 2016;21(4):123-30. 
11. Birklein F, O'Neill D, Schlereth T. Complex regional pain syndrome: an optimistic perspective. Neurology. 2015;84(1):89-96.

12. Llewellyn A, McCabe CS, Hibberd Y, White P, Davies L, Marinus J, et al. Are you better? A multi-centre study of patient-defined recovery from complex regional pain syndrome. Eur J Pain. 2018;22(3):551-64.

13. Atkinson L, Vile A. Unravelling the complex regional pain syndrome enigma. Pain Med 2020;21(2):225229.

14. Chang C, McDonnell P, Gershwin ME. Complex regional pain syndrome - false hopes and miscommunications. Autoimmun Rev. 2019;18(3):270-8.

15. Borchers AT, Gershwin ME. The clinical relevance of complex regional pain syndrome type I: The Emperor's New Clothes. Autoimmun Rev. 2017;16(1):22-33.

16.• Goebel A, Barker C, Birklein F, Brunner F, Casale R, Eccleston C, et al. Standards for the diagnosis and management of complex regional pain syndrome: results of a European Pain Federation task force. Eur J Pain. 2019;23(4):641-5.

A European Task Force recently published these 17 important standards for the diagnosis and management of CRPS.

17. Grieve S, Perez RSGM, Birklein F, Brunner F, Bruehl S, Harden RN, et al. Recommendations for a first Core Outcome Measurement set for complex regional PAin syndrome Clinical sTudies (COMPACT). Pain. 2017;158(6):1083.

18. de Mos M, de Bruijn AGJ, Huygen FJPM, Dieleman JP, Stricker BHC, Sturkenboom MCJM. The incidence of complex regional pain syndrome: a population-based study. Pain. 2007;129(1-2):12-20.

19. Elsharydah A, Loo NH, Minhajuddin A, Kandil ES. complex regional pain syndrome type 1

predictors-epidemiological perspective from a national database analysis. J Clin Anesth. 2017;39:34-7.

20. Bean DJ, Johnson MH, Kydd RR. The outcome of complex regional pain syndrome type 1: a systematic review. J Pain. 2014;15(7):677-90.

21. Van Velzen GAJ, Perez RSGM, Van Gestel MA, Huygen FJPM, Van Kleef M, Van Eijs F, et al. Health-related quality of life in 975 patients with complex regional pain syndrome type 1. Pain. 2014;155(3):629-34.

22. Scholz-Odermatt SM, Luthi F, Wertli MM, Brunner F. Direct health care cost and work incapacity related to complex regional pain syndrome in Switzerland: a retrospective analysis from 2008 to 2015 . Pain Med. 2019;20(8):1559-69.

23. Harden RN, Oaklander AL, Burton AW, Perez RSGM, Richardson K, Swan M. et Al. complex regional pain syndrome: practical diagnostic and treatment guidelines, 4th edition. Pain Med. 2013;14(2):180-22.

This article provides practical guidance for the diagnosis and treatment of CRPS.

24. Perez RGSM, Geertzen JHB, Dijkstra PU, Dirckx M, Van Eijs F, Frolke JP. Updated guidelines complex regional pain syndrome type 1 . Netherlands Society of Anaesthesiologists/Netherlands Society of Rehabilitation Specialists. Utrecht, Netherlands; 2014 [cited 2019
Feb 2]. Available from: https://www.crps-vereniging. nl/pdf/Executive_summary_guideline_CRPS_I_2014_ docx.pdf.

These updated guidelines provide recommendations for the diagnosis and treatment of CRPS.

25.• O'Connell NE, Wand BM, Mcauley J, Marston L, Moseley GL. Interventions for treating pain and disability in adults with complex regional pain syndromean overview of systematic reviews. Cochrane Database Syst Rev. 2013;4

This very useful Cochrane review summarised the evidence from a range of earlier Cochrane and non-Cochrane systematic reviews of CRPS treatments.

26. Cowell F, Gillespie S, Narayan B, Goebel A. Complex regional pain syndrome (CRPS) in orthopaedics: an overview. Orthop Traumatol. 2019;33(4):217-23.

27. Pons T, Shipton EA, Williman J, Mulder RT. A proposed clinical conceptual model for the physiotherapy management of complex regional pain syndrome (CRPS). Musculoskelet Sci Pract. 2018;38:15-22.

28. Daly AE, Bialocerkowski AE. Does evidence support physiotherapy management of adult complex regional pain syndrome type one? A systematic review. Eur J Pain. 2009;13(4):339-53.

29. Zečević Luković T, Ristić B, Jovanović Z, Rančić N, Ignjatović Ristić D, Cuković $S$. Complex regional pain syndrome type I in the upper extremity - how efficient physical therapy and rehabilitation are. Med Glas. 2012;9(2).

30. Elomaa M, Hotta J, De C, Williams AC, Forss N, Äyräpää A, et al. Symptom reduction and improved function in chronic CRPS type 1 after 12-week integrated, interdisciplinary therapy. Scand J Pain.

2019;19(2):257-70.

31. Oerlemans HM, Oostendorp RAB, De Boo T, Van Der Laan L, Severens JL, Goris RJA. Adjuvant physical therapy versus occupational therapy in patients with reflex sympathetic dystrophy/complex regional pain syndrome type i. Arch Phys Med Rehabil. 2000;81(1):49-56.

32. Rome L. The place of occupational therapy in rehabilitation strategies of complex regional pain syndrome: comparative study of 60 cases. Hand Surg Rehabil. 2016;35(5):355-62.

33. Packham TL, Spicher CJ, MacDermid JC, Michlovitz S, Buckley DN. Somatosensory rehabilitation for allodynia in complex regional pain syndrome of the upper limb: a retrospective cohort study. J Hand Ther. 2018;31(1):10-9.

34. Lewis JS, Kellett S, McCullough R, Tapper A, Tyler C, Viner $\mathrm{M}$, et al. Body perception disturbance and pain reduction in longstanding complex regional pain syndrome following a multidisciplinary rehabilitation program. Pain Med. 2019;20(11):2213-9.

35. Smart KM, Wand BM, O'Connell NE. Physiotherapy for pain and disability in adults with complex regional pain syndrome (CRPS) types I and II. Cochrane Database Syst Rev. 2016;2.

36. Morley S, Williams A, Hussain S. Estimating the clinical effectiveness of cognitive behavioural therapy in the clinic: evaluation of a CBT informed pain management programme. Pain. 2008;137(3):670-80. 
37. Scott EL, Kroenke K, Wu J, Yu Z. Beneficial effects of improvement in depression, pain catastrophizing, and anxiety on pain outcomes: a 12-month longitudinal analysis. J Pain. 2016;17(2):215-22.

38. Edwards RR, Dworkin RH, Sullivan MD, Turk DC, Wasan $\mathrm{AD}$. The role of psychosocial processes in the development and maintenance of chronic pain. J Pain. 2016;17(9):T70-92.

39. Linton SJ, Nicholas MK, MacDonald S, Boersma K, Bergbom S, Maher C, et al. The role of depression and catastrophizing in musculoskeletal pain. Eur J Pain. 2011;15(4):416-22.

40. Miller C, Williams M, Heine $\mathrm{P}$, Williamson E, O'connell N. Current practice in the rehabilitation of complex regional pain syndrome: a survey of practitioners. Disabil Rehabil. 2019;41(7):847-53 Available from: https://www.tandfonline.com/doi/full/10.1080/ 09638288.2017.1407968.

41. Beerthuizen A, Stronks DL, Van'T Spijker A, Yaksh A, Hanraets BM, Klein J, et al. Demographic and medical parameters in the development of complex regional pain syndrome type 1 (CRPS1): prospective study on 596 patients with a fracture. Pain. 2012;153(6):1187-92.

42. Bean DJ, Johnson MH, Heiss-Dunlop W, Kydd RR. Factors associated with disability and sick leave in early complex regional pain syndrome type- 1 . Clin J Pain. 2016;32(2):130-8.

43. Brinkers M, Rumpelt P, Lux A, Kretzschmar M, Pfau G. Psychiatric disorders in complex regional pain syndrome (CRPS): the role of the consultation-liaison psychiatrist. Pain Res Manag. 2018.

44. Sohn HS, Lee DH, Lee KJ, Noh EC, Choi SH, Jang JH, et al. Impaired empathic abilities among patients with complex regional pain syndrome (type I). Psychiatry Investig. 2016;13(1):34.

45. Bean DJ, Johnson MH, Kydd RR. Relationships between psychological factors, pain, and disability in complex regional pain syndrome and low back pain. Clin J Pain. 2014;30(8):647-53.

46. Dilek B, Yemez B, Kizil R, Kartal E, Gulbahar S, Sari O, et al. Anxious personality is a risk factor for developing complex regional pain syndrome type $i$. Rheumatol Int. 2012;32(4):915-20.

47. Harden RN, Bruehl S, Perez RSGM, Birklein F, Marinus J, Maihofner C, et al. Development of a severity score for CRPS. Pain. 2010;151(3):870-6.

48. Bean DJ, Johnson MH, Heiss-Dunlop W, Lee AC, Kydd RR. Do psychological factors influence recovery from complex regional pain syndrome type 1 ? A prospective study. Pain. 2015;156(11):2310-8.

49. De Jong JR, Vlaeyen JWS, De Gelder JM, Patijn J. Painrelated fear, perceived harmfulness of activities, and functional limitations in complex regional pain syndrome type i. J Pain. 2011;12(12):1209-18.

50. Vlaeyen JWS, Linton SJ. Fear-avoidance model of chronic musculoskeletal pain: 12 years on. Pain. 2012;153(6):1144-7.

51. Schulte-Goecking H, Azqueta-Gavaldon M, Storz C, Woiczinski M, Fraenkel P, Leukert J, et al.
Psychological, social and biological correlates of body perception disturbance in complex regional pain syndrome. Curr Psychol. 2020:1-11.

52. Bruehl S. Complex regional pain syndrome. BMJ. 2015;(351):h2730.

53. Lewis JS, Coales K, Hall J, McCabe CS. 'Now you see it, now you do not': sensory-motor re-education in complex regional pain syndrome. Hand Ther. 2011;16(2):29-38.

54. Speck V, Schlereth T, Birklein F, Maihöfner C. Increased prevalence of posttraumatic stress disorder in CRPS. Eur J Pain. 2017;21(3):466-73.

55. Rand SE, Basu S, Khalid S. complex regional pain syndrome: current diagnostic and treatment considerations. Curr Sports Med Rep. 2019;18(9):325-9.

56. Beerthuizen A, Stronks DL, Huygen FJPM, Passchier J, Klein J, Spijker AVT. The association between psychological factors and the development of complex regional pain syndrome type 1 (CRPS1) - a prospective multicenter study. Eur J Pain. 2011;15(9):971-5.

57. Castelnuovo G, Giusti EM, Manzoni GM, Saviola D, Gatti A, Gabrielli S, et al. Psychological treatments and psychotherapies in the neurorehabilitation of pain: evidences and recommendations from the italian consensus conference on pain in neurorehabilitation. Front Psychol. 2016;7:115.

58. Sweeting MJ, Llewellyn A, McCabe C. Living with complex regional pain syndrome: identifying the biopsychosocial impacts to inform rehabilitation practice. In: Clinical Rehabilitation. 2018. p. 1410.

59. Packham T, Holly J. Mechanism-specific rehabilitation management of complex regional pain syndrome: proposed recommendations from evidence synthesis. J Hand Ther. 2018;31(2):238-49.

60. Graffigna G, Barello S. Patient engagement in healthcare: pathways for effective medical decision making. Neuropsychol Trends. 2015;17:53-65.

61. Brunner F, Gymesi A, Kissling R, Bachmann L. Diseaserelated knowledge of patients with chronic regional pain syndrome. J Rehabil Med. 2010;42(5):458-62.

62. Grieve S, Adams J, Mccabe C. "What I Really Needed Was the Truth". Exploring the information needs of people with complex regional pain syndrome. Musculoskeletal Care 2016;14(1):15-25.

63. Louw A, Zimney K, Cox T, O'Hotto C, Wassinger CA. The experiences and beliefs of patients with complex regional pain syndrome: an exploratory survey study. Chronic Illn. 2018;14(2):104-18.

64. Rodham K, Gavin J, Coulson N, Watts L. Co-creation of information leaflets to meet the support needs of people living with complex regional pain syndrome (CRPS) through innovative use of wiki technology. Informatics Heal Soc Care. 2016;41(3):325-39.

65. Rodham K, McCabe C, Pilkington M, Regan L. Coping with chronic complex regional pain syndrome: advice from patients for patients. Chronic Illn. 2013;9(1):29-42.

66. Packham J, Arkell P, Sheeran T, Brownfield A, Cadwgan A, Ryan S. Patient experiences, attitudes and expectations towards receiving information about anti-TNF 
medication: a quantitative study. Clin Rheumatol. 2017;36(11):2595-600.

67. Garneau K, Iversen M, Jan S, Parmar K, Tsao P, Solomon DH. Rheumatoid arthritis decision making: many information sources but not all rated as useful. J Clin Rheumatol. 2011;17(5):231-5.

68. O'Connor AM, Mulley AG, Wennberg JE. Standard consultations are not enough to ensure decision quality regarding preference-sensitive options. J Natl Cancer Inst. 2003;95(8):570-1.

69. McKernan L, Koval T. Integrative clinical hypnosis and massage therapy in treatment-refractory chronic regional pain syndrome-1. Glob Adv Heal Med. 2018;7:144.

70. Halicka M, Vittersø AD, McCullough H, Goebel A, Heelas L, Proulx MJ, et al. Disputing space-based biases in unilateral complex regional pain syndrome. Cortex. 2020.

71. Halicka M, Vittersø AD, Proulx MJ, Bultitude JH. Neuropsychological changes in complex regional pain syndrome (CRPS). Behav Neurol. 2020.

72. McCabe CS, Haigh RC, Shenker NG, Lewis J, Blake DR, Pisetsky, et al. Phantoms in rheumatology. Novartis Foundation Symposium. Chichster; New York: John Wiley; 2004. 154-178 p.

73. Lewis JS, Kersten P, McCabe CS, McPherson KM, Blake DR. Body perception disturbance: a contribution to pain in complex regional pain syndrome (CRPS). Pain. 2007;133(1-3):111-9.

74. Lewis JS, Kersten P, McPherson KM, Taylor GJ, Harris $\mathrm{N}$, McCabe CS, et al. Wherever is my arm? Impaired upper limb position accuracy in complex regional pain syndrome. Pain. 2010;149(3):463-9.

75. Cohen HE, Hall J, Harris N, McCabe CS, Blake DR, Jänig W. Enhanced pain and autonomic responses to ambiguous visual stimuli in chronic complex regional pain syndrome (CRPS) type I. Eur J Pain. 2012;16(2):182-95.

76. Bultitude JH, Walker I, Spence C. Space-based bias of covert visual attention in complex regional pain syndrome. Brain. 2017;140(9):2306-21.

77. Moseley GL, Gallace A, Spence C. Space-based, but not arm-based, shift in tactile processing in complex regional pain syndrome and its relationship to cooling of the affected limb. Brain. 2009;132(11):3142-51.

78. Bultitude JH, Rafal RD. Derangement of body representation in complex regional pain syndrome: report of a case treated with mirror and prisms. Exp Brain Res. 2010;204(3):409-18.

79. Christophe L, Chabanat E, Delporte L, Revol P, Volckmann P, Jacquin-Courtois S, et al. Prisms to shift pain away: pathophysiological and therapeutic exploration of CRPS with prism adaptation. Neural Plast. 2016.

80. Sumitani M, Rossetti Y, Shibata M, Matsuda Y, Sakaue $\mathrm{G}$, Inoue $\mathrm{T}$, et al. Prism adaptation to optical deviation alleviates pathologic pain. Neurology. 2007;68(2):128-33.

81. Halicka M, Vittersø AD, Proulx MJ, Bultitude JH. Pain reduction by inducing sensory-motor adaptation in complex regional pain syndrome (CRPS PRISMA): protocol for a double-blind randomized controlled trial. BMC Neurol. 2020;20(62).

82. Rodríguez Larrad A, Rizzello C, Perfetti C, Panté F, Zernitz M: Ejercicio Terpéutico Cognoscitivo. In: Cano de la Cureda R, Collado Vazquez S, editors. Neurorrehabilitación métodos específicos valoración y Tratamiento. Madrid: Medica Panamericana; 2012.

83. Sallés L, Martín-Casas $\mathrm{P}$, Gironès $\mathrm{X}$, Durà MJ, Lafuente $\mathrm{JV}$, Perfetti C. A neurocognitive approach for recovering upper extremity movement following subacute stroke: a randomized controlled pilot study. J Phys Ther Sci. 2017;29(4):665-72.

84. Sallés L, Gironès X, Martín-Casas P, Lafuente JV. A neurocognitive approach to recovery of movement following stroke. Phys Ther Rev. 2015;20(5-6):283-9.

85. Marzetti E, Rabini A, Piccinini G, Piazzini DB, Vulpiani $M C$, Vetrano M, et al. Neurocognitive therapeutic exercise improves pain and function in patients with shoulder impingement syndrome: a single-blind randomized controlled clinical trial. Eur J Phys Rehabil Med. 2014;50(3):225-64.

86. Cappellino F, Paolucci T, Zangrando F, Iosa M, Adriani $\mathrm{E}$, Mancini $\mathrm{P}$, et al. Neurocognitive rehabilitative approach effectiveness after anterior cruciate ligament reconstruction with patellar tendon. A randomized controlled trial. Eur J Phys Rehabil Med.

2012;48(1):17-30.

87. Zangrando F, Piccinini G, Pelliccioni A, Saraceni VM, Paolucci T. Neurocognitive rehabilitation in Parkinson's disease with motor imagery: a rehabilitative experience in a case report. Case Rep Med. 2015.

88. Moseley GL. Is successful rehabilitation of complex regional pain syndrome due to sustained attention to the affected limb? A randomised clinical trial. Pain. 2005; 114(1-2):54-61.

89. Lewis JS, Newport R, Mccabe CS. Changing appearance using visual illusons improves ownership of the painful hand in complex regional pain syndrome. In: European Pain Federation EFIC 9th Congress. 2015. p. 5-6. Available from: /uwe-repository.worktribe.com/output/828533

90. Lewis JS, Newport R, Taylor G, Smith M, McCabe C. Changing hand appearance using visual illusions modulates body perception disturbance and pain in longstanding Complex Regional Pain Syndrome: a randomised trial. medRxiv. 2020;2020.02.26.20020420. Available from: http:// medrxiv.org/content/early/2020/02/27/2020.02.26. 20020420.abstract.

91. Botvinick M, Cohen J. Rubber hands "feel" touch that eyes see [8]. Nature. 1998;391(6669):756.

92. McCabe CS, Cohen H, Hall J, Lewis J, Rodham K, Harris N. Somatosensory conflicts in complex regional pain syndrome type 1 and fibromyalgia syndrome. Curr Rheumatol Rep. 2009;11(6):461.

93. Flor H, Denke C, Schaefer M, Grüsser S. Effect of sensory discrimination training on cortical reorganisation and phantom limb pain. Lancet. 2001;357(9270):1763-4. 
94. Moseley GL, Zalucki NM, Wiech K. Tactile discrimination, but not tactile stimulation alone, reduces chronic limb pain. Pain. 2008;137(3):600-8.

95. Schmid AC, Schwarz A, Gustin SM, Greenspan JD, Hummel FC, Birbaumer N. Pain reduction due to novel sensory-motor training in complex regional pain syndrome I - a pilot study. Scand J Pain.

2017;15(1):30-7.

96. Grieve S, Hart D, Harrison N, Palmer M, Taylor P, Turton A, et al. Electrical sensory discrimination therapy in complex regional pain syndrome. In: 5th International Congress on Neuropathic Pain. 2015.
Available from: https://uwe-repository.worktribe.com/ output/842219.

\section{Publisher's Note}

Springer Nature remains neutral with regard to jurisdictional claims in published maps and institutional affiliations. 